\title{
Experimental dynamic analysis of the existing footbridge in Dobřichovice town
}

\author{
Michal Polák ${ }^{1, *}$, Tomáš Plachý1 ${ }^{1}$ Adam Cítek $^{2}$, Karolína Berková $^{1}$, Petra Hájková $^{2}$ and \\ Miroslav Č́p ${ }^{1}$ \\ ${ }^{1}$ Czech Technical University in Prague, Faculty of Civil Engineering, Department of Mechanics, \\ Thákurova 7, Prague 6, 166 29, Czech Republic \\ ${ }^{2}$ Czech Technical University in Prague, Klokner institute, Šolínova 7, Prague 6, 166 08, Czech \\ Republic
}

\begin{abstract}
The paper presents an experimental dynamic analysis of the existing footbridge across the Berounka River in Dobřichovice town, Czech Republic. The experiment was realized in two stages. The main purpose of the first one was the vibration response determination of the footbridge induced by pedestrians. At first, the natural frequencies and mode shapes of its horizontal load-bearing structure were measured and then the footbridge was loaded by different groups of pedestrians. The response was observed and dynamic behaviour of the footbridge was evaluated. In the course of the second stage of the experiment, the dynamic response of the footbridge deck to pedestrian traffic was measured by two different methods using radar interferometry and classical approach realized by piezoelectric accelerometers. Basic objectives of the second stage were to evaluate the fundamental modal characteristics of the footbridge and to verify new approach to dynamic response measurement - radar interferometry realized by two synchronized radars.
\end{abstract}

\section{Introduction}

The experimental dynamic analysis described in this paper was focused on the existing footbridge across the Berounka River in Dobrrichovice town. The potential higher sensitivity of the footbridge deck to the dynamic effects of pedestrian traffic was already known from the footbridge design stage. However, the dynamic loading test was not realized before the footbridge was put into operation.

The described experiment was performed in two stages. The first one was carried out in April 2017. It was especially focused on the experimental analysis of the vibration response of the horizontal load bearing structure induced by pedestrian traffic and the comfort limit verification. The natural frequencies and corresponding mode shapes were then also evaluated.

The second stage of the experiment was performed in December 2019 when the dynamic response of the footbridge deck to pedestrian traffic was measured by two different methods using classical approach $[1,2]$ carried out by six piezoelectric accelerometers and radar

* Corresponding author: polak@fsv.cvut.cz 
interferometry [3-5]. Basic objectives of the second stage were to evaluate the fundamental modal characteristics of the footbridge and to verify new approach to dynamic response measurement - radar interferometry realized by two synchronized radars.

Similar experiments on bridge structures using radar interferometry performed by one radar only are for example described in [6-9].

\section{Description of the footbridge}

The footbridge is located in Dobřichovice town near Prague, where it crosses the Berounka River. It is an important pedestrian way between two parts of Dobřichovice separated by the river - the town and a railway station.

The studied footbridge was built in 2003 as a replacement for the original one, which was destroyed during the extreme flood in August 2002. The aim of the footbridge project was to design a structure that is not only of high quality and meets current standards, but also to be able to withstand floods of similar size to the one in 2002. For this reason, it also bridges inundation area on the left bank of the Berounka River (see Fig. 1).

It is a cable stayed footbridge with 2 spans $88 \mathrm{~m}$ and $92 \mathrm{~m}$ long. The horizontal loadbearing structure is a composite structure with two main steel girders and a lower reinforced concrete deck. The width of the horizontal load-bearing structure is $3.80 \mathrm{~m}$ and its total length is $180.60 \mathrm{~m}$. The width of the free space for walking is $3.00 \mathrm{~m}$. The longitudinal slope of the footbridge deck varies along the length from $+2.55 \%$ to $-2.4 \%$.

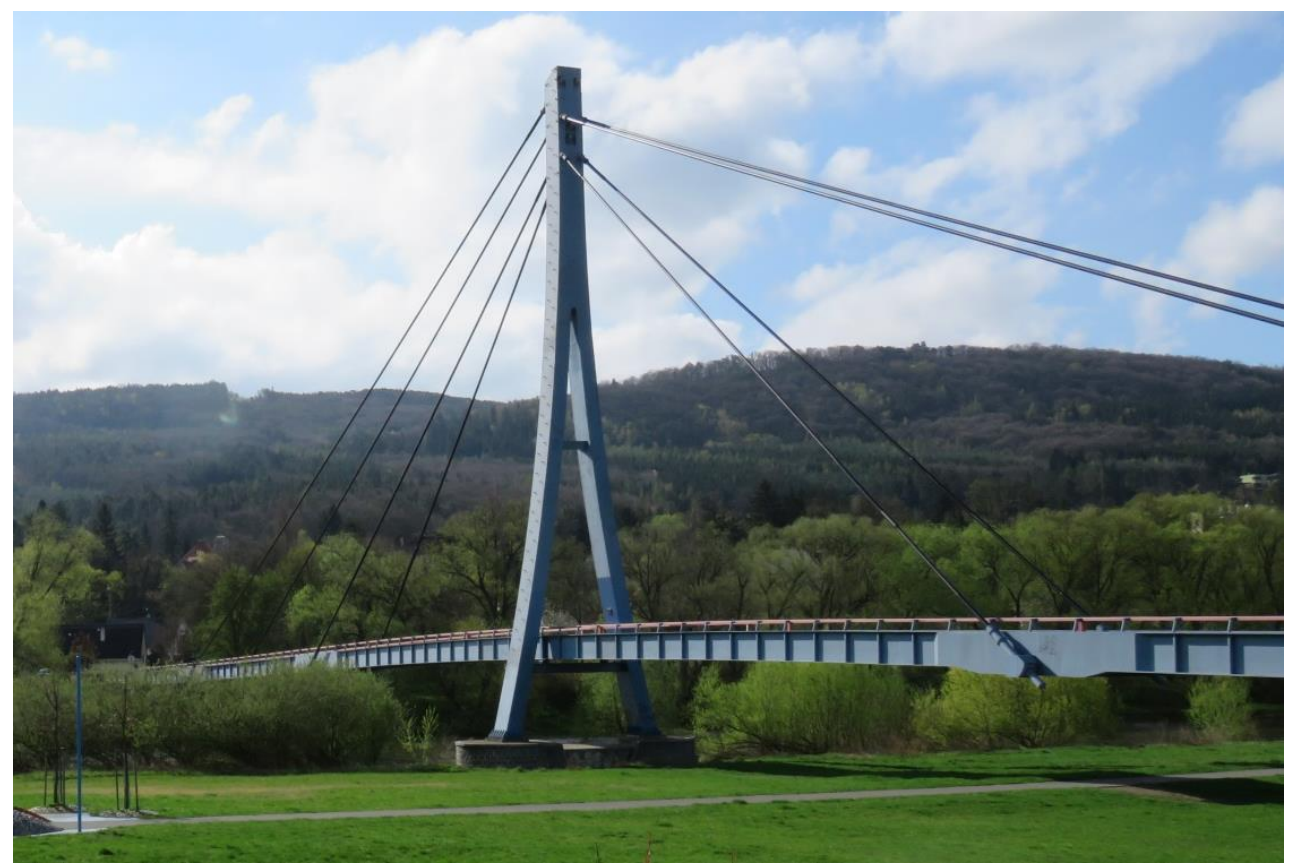

Fig. 1. The analysed footbridge in Dobřichovice town.

The horizontal load-bearing structure is suspended on a $34.6 \mathrm{~m}$ high A-shaped steel pylon by means of a system of 4 pairs of stays (see Fig. 1). The stays are made up of 14 prestressing strands (shorter suspensions) and 16 prestressing strands (longer suspensions). As was said above, the horizontal load-bearing structure consists of two main welded steel I shaped girders of variable height from $1200 \mathrm{~mm}$ to $1400 \mathrm{~mm}$. The axial distance of the main girders is $3400 \mathrm{~mm}$ over the entire footbridge. In the area of anchorage of the stays, the main girders 
are increased to the height $1400 \mathrm{~mm}$. In this area, the girder cross section changes smoothly from the I shape to a closed rectangular one. The change of the girder height is realized only on the lower flange of the girders (see Fig. 1). At an axial distance of $2.0 \mathrm{~m}$, the main girders are reinforced vertically by steel transverse stiffeners with a thickness of $6 \mathrm{~mm}$ (see Fig. 1). The main girders are interconnected by steel cross girders of the I- below the concrete deck at the axial distance of $2 \mathrm{~m}$ (at the places of the transverse stiffeners). The bridge deck consists of a composite reinforced concrete slab (concrete C30 / 37 - XF1) and its thickness varies in the interval from $120.0 \mathrm{~mm}$ to $142.5 \mathrm{~mm}$. The dewatering of the footbridge deck is realized by a cross slope of $1.5 \%$, where gullies are located at an axial distance of $10 \mathrm{~m}$.

Both abutments are founded on 6 reinfoced concrete micropiles of $4.0 \mathrm{~m}$ length and the pylon is anchored on a reinforced concrete footing, which is founded on 8 large-diameter reinforced concrete piles. The whole substructure is made of concrete C30 / 37 - XF1.

The horizontal load-bearing structure is supported on the abutments by pairs of transversely fixed pot bearings with a teflon slide, which enables overall longitudinal displacement of $120 \mathrm{~mm}$. On the pylon, the main girders are supported by a pair of pot bearings which don't enable any displacement of the structure. The footbridge expansion is thus realized in both directions from the pylon to the outer supports, where the simple steel surface expansion joints are installed.

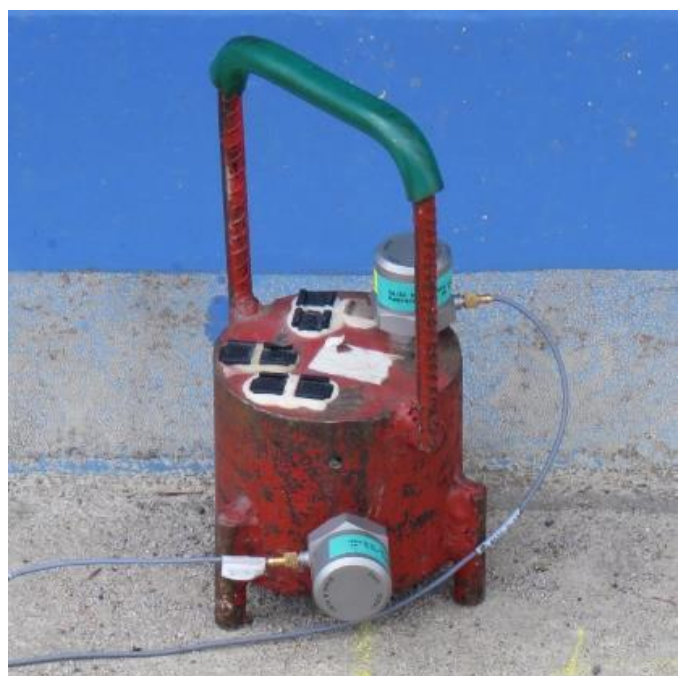

Fig. 2. Two acceleration transducers Brüel \& Kjær Type 8344 attached to the steel weight.

\section{Experimental modal analysis}

As was said above, no dynamic experiment has ever been performed on that structure and the actual modal characteristics of the structure have not been known until the first stage of the dynamic experiment was performed there on $6^{\text {th }}$ April 2017. The aim of the experimental modal analysis was to find out the real natural frequencies and modes of vibration of the footbridge structure and then compare them with theoretical ones.

\subsection{Measurement line}

In the course of the first experiment stage, the bridge vibration was measured by piezoelectric acceleration transducers Brüel \& Kjær Type 8344. The working range of these sensors is from $0.2 \mathrm{~Hz}$ to $3 \mathrm{kHz}$, and they have very high sensitivity of approximately $2500 \mathrm{mV} / \mathrm{g}$ and 
a natural frequency of $10 \mathrm{kHz}$. During the measurement, the sensors were magnetically attached to steel weights (see Fig. 2) and via cables connected to the 4-channel data acquisition station Brüel \& Kjær Type 3050-B with maximum frequency range $51.2 \mathrm{kHz}$ and with $2 \times 24$-bit A / D converter. During the experimental modal analysis of the footbridge, the data were recorded by PULSE software Brüel \& Kjær. Subsequent analysis of the records was performed with ME'scope VES software Vibrant Technology Inc.

\subsection{Measurement system}

In the preparation phase of the experiment, the low damping of the analysed footbridge was supposed because it is a steel composite structure. Thus, the Ambient Vibration Testing (AVT) system was chosen for the experimental modal analysis. During this method, the excitation forces are not measured and therefore the recorded dynamic responses were normalized to the one observed in the reference point. The assumed low damping and real dimensions of the structure suggested that the response of the footbridge should be sufficient for this method. During this variant of the experiment the pedestrian traffic on the footbridge could not be interrupted or restricted and the possible use of the exciter and the Forced Vibration Testing (FVT) method would not be a suitable and also economical solution. The inappropriateness of the FVT method in this case consisted especially in the fact that the controlled excitation force has to be measured in the course of this method and effects of other uncontrolled dynamic forces are unwanted because the recorded dynamic responses are standardly normalized to the excitation force which caused them.

Seventeen cross-sections were selected for the experimental modal analysis. Such a number of cross-sections was chosen to evaluate a sufficient number of mode shapes and also to be able to carry out the whole experiment in one day. Two points were measured in each cross-section and they were located approximately $5 \mathrm{~cm}$ from the left and right web of the main girders. The measured points were marked with the number of the respective crosssection from 1 to 17 and with the number 1 or 2 for the position in the section ( 1 means the left side of the deck and 2 the right side), e.g. number 162 means the point in the $16^{\text {th }}$ crosssection on the right side of the footbridge. The positions of the measured cross-sections with marked observed points are visible in a simplified ground plan in Fig. 3.

The reference acceleration transducer position was chosen based on the eigenmodes obtained by theoretical dynamic analysis. The reference position was located $3 \mathrm{~m}$ behind the first anchorage of the stays in the first footbridge span-(see Fig. 3). It was evaluated as the best position because of the most of calculated eigenmodes up to $5 \mathrm{~Hz}$ had at least some sufficiently high ordinate to measure their shapes. Only horizontal bending modes and some torsional modes should be problematic to measure because they should have higher ordinates in the second span according to the theoretical analysis.

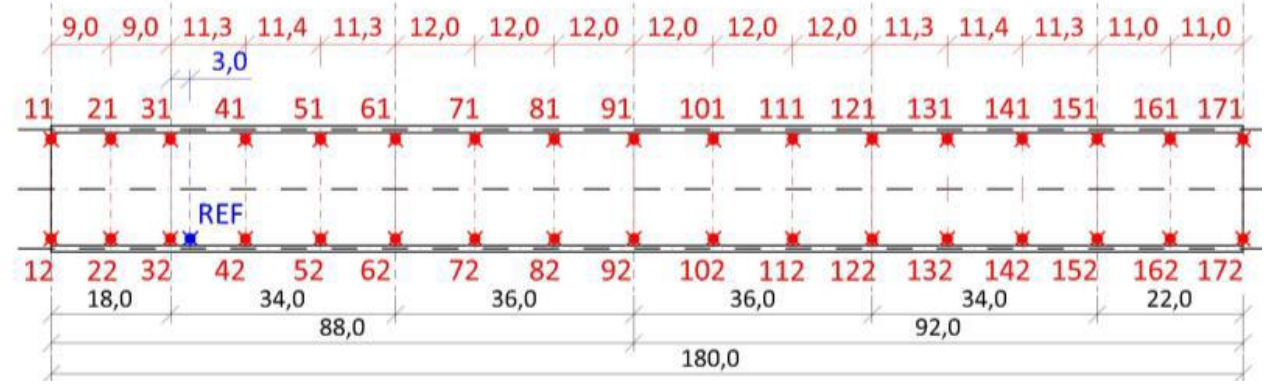

Fig. 3. The simplified ground plan of the footbridge with the marked observed points. 
The vibration of the construction was excited by force impulses caused by people jumping in intervals depended on the time when the amplitude decreases to unmeasurable range. The cross-section with the reference sensor has been chosen as the most suitable place for excitation of the footbridge structure. The same requirements were applied for the selection of the excitation point as for the reference point selection.

The dynamic response was observed by four acceleration transducers attached by a magnet to steel weights placed on the deck (see Fig. 2). At points on the left side it was measured only vertically, at points on the right side vertically and horizontally (in the direction perpendicular to the longitudinal axis of the footbridge) and only vertically at the reference point. The position of the reference sensor did not change during the whole experiment. The vibration in each cross-section was measured for five minutes to acquire the data sufficient for averaging in FFT with appropriate precision.

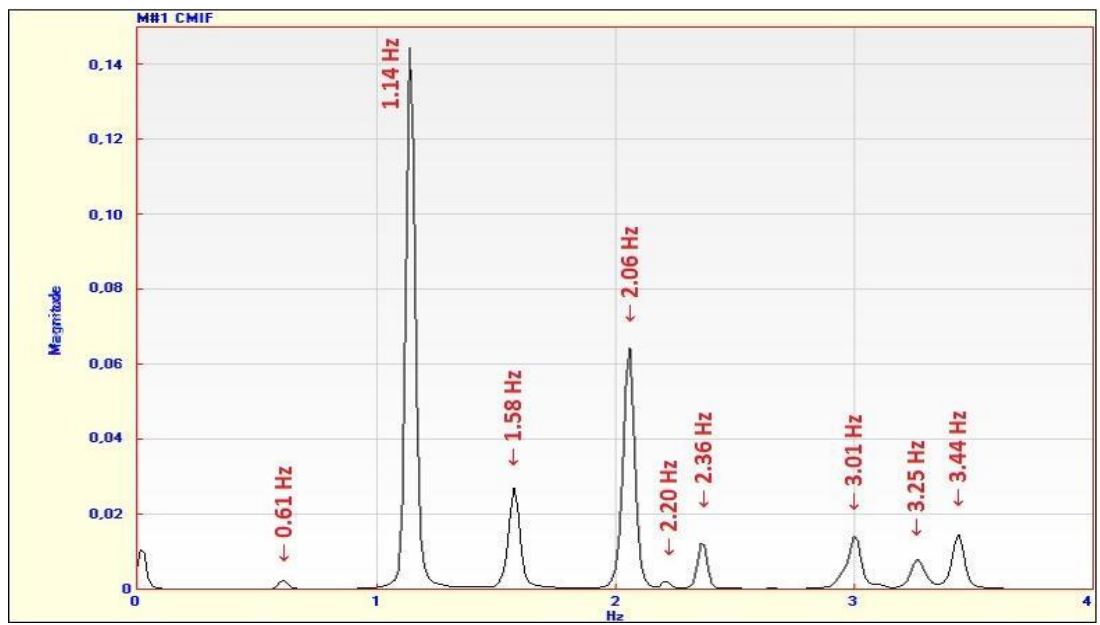

Fig. 4. Evaluated Complex Mode Indicator Function (CMIF) with marked identified natural frequencies of the footbridge.

Table 1. Natural frequencies of the footbridge evaluated during the first stage of the experiment.

\begin{tabular}{|c|c|l|}
\hline No.: & $\begin{array}{c}\mathbf{f}(\mathbf{j}) \\
{[\mathbf{H z}]}\end{array}$ & Character of the natural mode \\
\hline$(1)$ & 0.61 & $1^{\text {st }}$ vertical bending mode of vibration \\
\hline$(2)$ & 1.14 & $2^{\text {nd }}$ vertical bending mode of vibration \\
\hline$(3)$ & 1.58 & $3^{\text {rd }}$ vertical bending mode of vibration \\
\hline$(4)$ & 2.06 & $4^{\text {th }}$ vertical bending mode of vibration \\
\hline$(5)$ & 2.20 & $1^{\text {st }}$ torsional mode of vibration \\
\hline$(6)$ & 2.36 & $2^{\text {nd }}$ torsional mode of vibration \\
\hline$(7)$ & 3.01 & $5^{\text {th }}$ vertical bending mode of vibration \\
\hline$(8)$ & 3.25 & $3^{\text {rd }}$ torsional mode of vibration \\
\hline$(9)$ & 3.45 & $6^{\text {th }}$ vertical bending mode of vibration \\
\hline
\end{tabular}



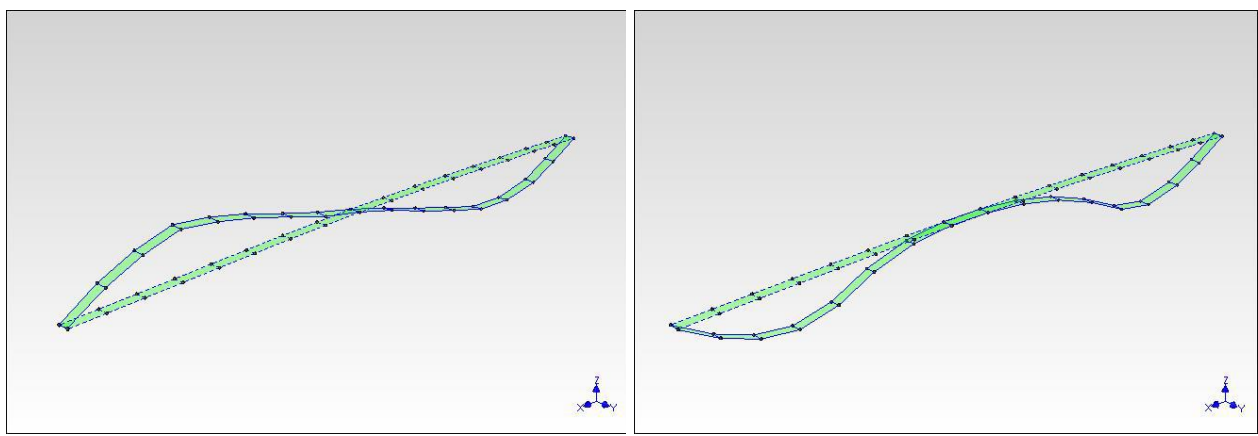

Fig. 5. The $1^{\text {st }}$ and $2^{\text {nd }}$ natural modes of vibration.
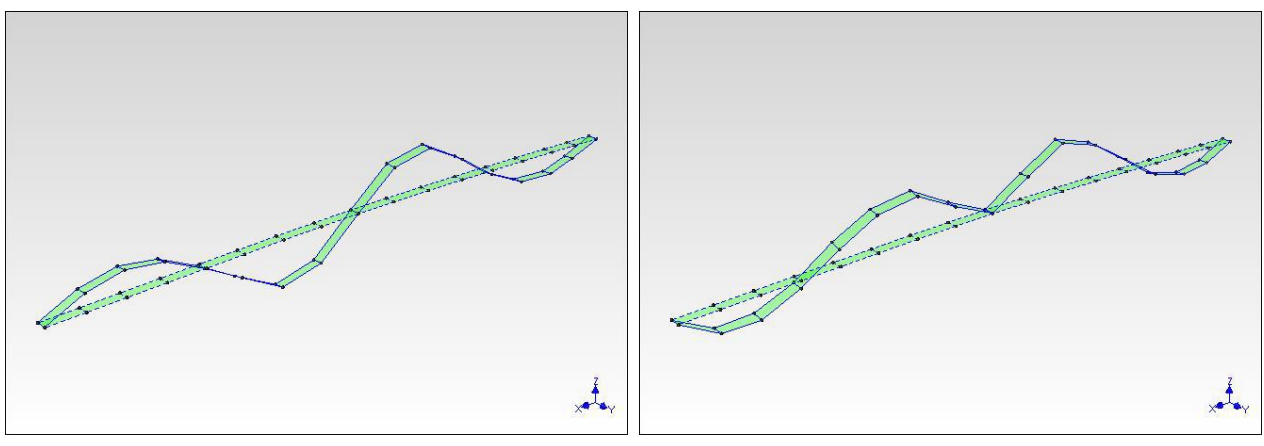

Fig. 6. The $3^{\text {rd }}$ and $4^{\text {th }}$ natural modes of vibration.

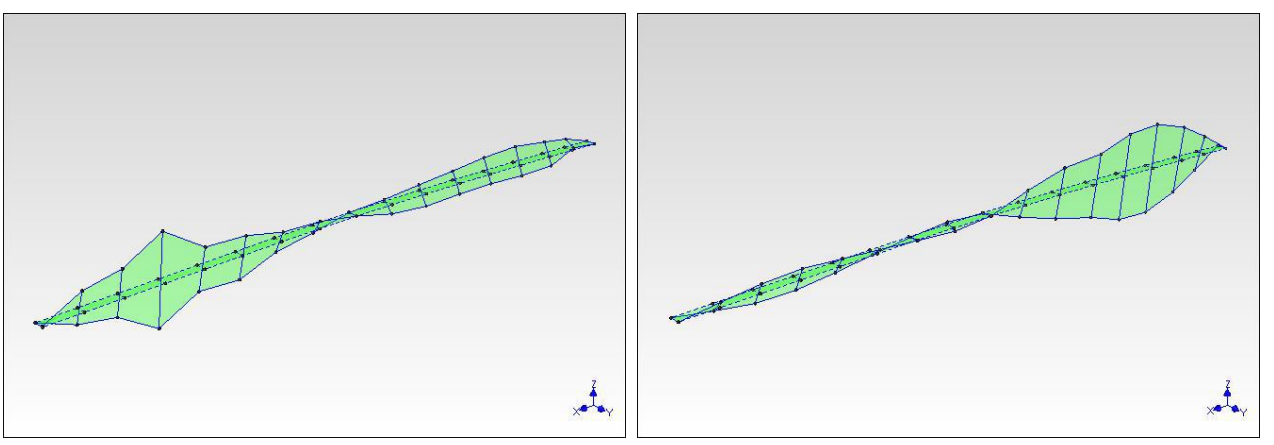

Fig. 7. The $5^{\text {th }}$ and $6^{\text {th }}$ natural modes of vibration.
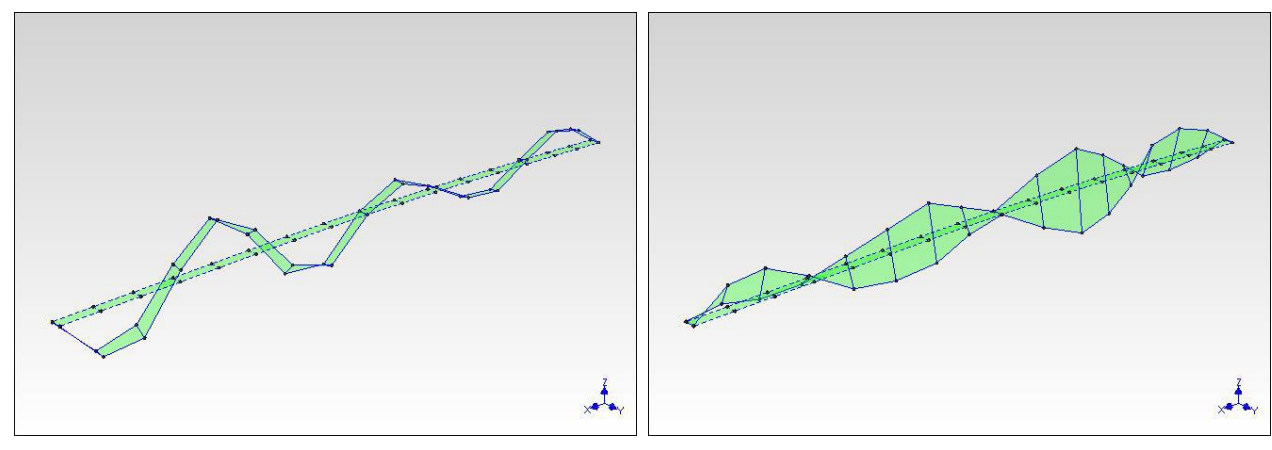

Fig. 8. The $7^{\text {th }}$ and $8^{\text {th }}$ natural modes of vibration. 


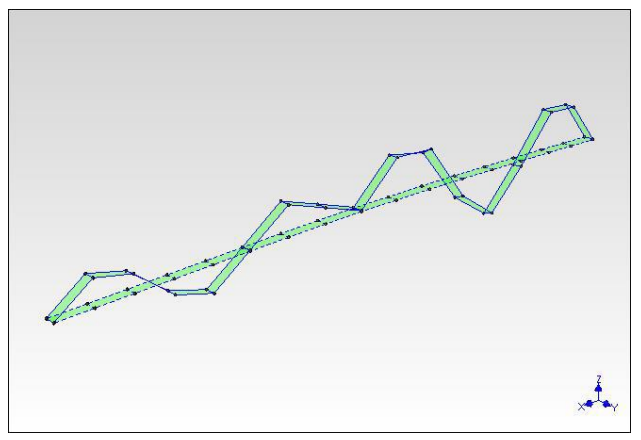

Fig. 9. The $9^{\text {th }}$ natural mode of vibration.

\subsection{Evaluation of the natural frequencies and mode shapes}

Measured records of the dynamic response were processed in ME'scopeVES. At first, the data from all channels were transformed using Fast Fourier Transform (FFT) from time domain to the frequency domain. Frequency transfer functions of the operational deflection shapes (ODS FRF) were evaluated from these signals for all 34 measured points. The natural frequencies were evaluated from Complex Mode Indicator Function (CMIF), which is defined as the eigen values solved from the normal matrix, which is formed from frequency response function (FRF) matrix. CMIF can be computed from multiplication of normal matrix with its Hermitian matrix or by singular value decomposition (SVD) of normal matrix at each spectral line $[10,11]$. The first nine natural frequencies (see Table 1 and Fig. 4) and mode shapes (see Figs. 5-9) were evaluated.

\subsection{Comparison of the measured and calculated natural frequencies and mode shapes}

The measured modal characteristics of the footbridge were compared with the calculated ones. The mutual assignment of the calculated and measured modes were done using the Modal Assurance Criterion (MAC). The values of the MAC are shown in Table 2.

Table 2. Comparison of the measured and calculated natural modes using MAC.

\begin{tabular}{|c|c|c|c|c|c|c|c|c|c|c|c|c|}
\hline MAC & \multicolumn{10}{|c|}{ Theoretical calculation } \\
\hline Experiment & 0.60 & 1.13 & 1.52 & 1.66 & 1.72 & 2.09 & 2.29 & 2.49 & 3.1 & 3.11 & 3.19 & 3.58 \\
\hline $0.61 \mathrm{~Hz}$ & $\mathbf{1 . 0 0}$ & 0.00 & 0.00 & 0.00 & 0.00 & 0.00 & 0.00 & 0.00 & 0.00 & 0.00 & 0.00 & 0.00 \\
\hline $1.14 \mathrm{~Hz}$ & 0.00 & $\mathbf{0 . 9 9}$ & 0.00 & 0.00 & 0.00 & 0.00 & 0.00 & 0.00 & 0.00 & 0.00 & 0.00 & 0.00 \\
\hline $1.58 \mathrm{~Hz}$ & 0.00 & 0.00 & 0.00 & $\mathbf{0 . 9 9}$ & 0.00 & 0.00 & 0.00 & 0.00 & 0.00 & 0.01 & 0.00 & 0.00 \\
\hline $2.06 \mathrm{~Hz}$ & 0.00 & 0.00 & 0.00 & 0.00 & 0.00 & $\mathbf{0 . 9 9}$ & 0.00 & 0.00 & 0.00 & 0.00 & 0.00 & 0.00 \\
\hline $2.20 \mathrm{~Hz}$ & 0.00 & 0.00 & 0.03 & 0.01 & 0.00 & 0.03 & $\mathbf{0 . 8 2}$ & 0.02 & 0.01 & 0.00 & 0.00 & 0.00 \\
\hline $2.36 \mathrm{~Hz}$ & 0.00 & 0.00 & 0.00 & 0.00 & 0.06 & 0.00 & 0.06 & $\mathbf{0 . 8 8}$ & 0.00 & 0.00 & 0.03 & 0.00 \\
\hline $3.01 \mathrm{~Hz}$ & 0.00 & 0.00 & 0.00 & 0.00 & 0.00 & 0.00 & 0.00 & 0.00 & 0.03 & $\mathbf{0 . 9 5}$ & 0.00 & 0.00 \\
\hline $3.25 \mathrm{~Hz}$ & 0.00 & 0.00 & 0.00 & 0.00 & 0.00 & 0.00 & 0.00 & 0.01 & 0.02 & 0.03 & $\mathbf{0 . 8 9}$ & 0.03 \\
\hline $3.45 \mathrm{~Hz}$ & 0.00 & 0.00 & 0.00 & 0.00 & 0.00 & 0.00 & 0.00 & 0.00 & 0.00 & 0.00 & 0.00 & $\mathbf{0 . 9 9}$ \\
\hline
\end{tabular}


Table 3. Comparison of the calculated and measured natural frequencies of the footbridge.

\begin{tabular}{|l|l|c|c|c|c|}
\hline Order & $\begin{array}{l}\text { Character } \\
\text { of the natural mode }\end{array}$ & $\begin{array}{c}\text { Experimental } \\
\boldsymbol{f ( j )} \\
{[\mathbf{H z}]}\end{array}$ & $\begin{array}{c}\text { Theoretical } \\
\boldsymbol{f ( \boldsymbol { k } )} \\
{[\mathbf{H z}]}\end{array}$ & $\begin{array}{c}\Delta(\boldsymbol{j}, \boldsymbol{k}) \\
{[\mathbf{\%}]}\end{array}$ & $\begin{array}{c}\text { Limit } \\
\text { deviation } \\
{[\%]}\end{array}$ \\
\hline$(1)$ & $1^{\text {st }}$ vertical bending mode & 0.61 & 0.60 & -0.83 & $+10 ;-15.0$ \\
\hline$(2)$ & $2^{\text {nd }}$ vertical bending mode & 1.14 & 1.13 & -0.97 & \pm 15.9 \\
\hline$(3)$ & $1^{\text {st }}$ horizontal bending mode & - & 1.52 & - & - \\
\hline$(4)$ & $3^{\text {rd }}$ vertical bending mode & 1.58 & 1.66 & 4.71 & \pm 16.8 \\
\hline$(5)$ & $2^{\text {nd }}$ horizontal bending mode & - & 1.72 & - & - \\
\hline$(6)$ & $4^{\text {th }}$ vertical bending mode & 2.06 & 2.09 & 1.29 & \pm 17.5 \\
\hline$(7)$ & $1^{\text {st }}$ torsional mode & 2.20 & 2.29 & 3.63 & \pm 17.8 \\
\hline$(8)$ & $2^{\text {nd }}$ torsional mode & 2.36 & 2.49 & 5.18 & \pm 18.2 \\
\hline$(9)$ & $3^{\text {rd }}$ torsional mode & - & 3.10 & - & - \\
\hline$(10)$ & $5^{\text {th }}$ vertical bending mode & 3.01 & 3.11 & 3.08 & \pm 19.2 \\
\hline$(11)$ & $4^{\text {th }}$ torsional mode & 3.25 & 3.19 & -1.82 & \pm 19.3 \\
\hline$(12)$ & $6^{\text {th }}$ vertical bending mode & 3.45 & 3.58 & 3.47 & \pm 20.0 \\
\hline
\end{tabular}

The experimental modal analysis did not identify two horizontal bending modes and one torsional mode from the theoretical analysis because these modes had minimal ordinates at the position and measurement direction of the reference transducer.

The calculated differences between corresponding natural frequencies are low and satisfy the limit deviations according to Czech standard ČSN 736209:1996 (see Table 3). For the experimental torsional modes, a lower shape matching with the calculated ones was achieved, but in all three cases relevant MAC was always greater than $0.80(80 \%)$.

\subsection{Comparison of the measured natural frequencies in 2017 and 2019}

The new set of measurements was performed in December 2019. The basic reason for these experiments realized on the footbridge was to evaluate the fundamental modal characteristics of the footbridge and to verify new method of dynamic response measurement - radar interferometry realized by two synchronized radars (see Fig. 10).

Table 4. Comparison of the natural frequencies of the footbridge measured in 2017 and 2019.

\begin{tabular}{|l|l|c|c|}
\hline Order & Character of the natural mode & $\begin{array}{c}\mathbf{2 0 1 7} \\
\boldsymbol{f ( j )} \\
{[\mathbf{H z}]}\end{array}$ & $\begin{array}{c}\mathbf{2 0 1 9} \\
\boldsymbol{f ( \boldsymbol { k } )} \\
{[\mathbf{H z}]}\end{array}$ \\
\hline$(1)$ & & 0.61 & 0.61 \\
\hline$(2)$ & $1^{\text {st }}$ vertical bending mode & 1.14 & 1.14 \\
\hline$(3)$ & $2^{\text {nd }}$ vertical bending mode & - & - \\
\hline$(4)$ & $1^{\text {st }}$ horizontal bending mode & 1.58 & 1.58 \\
\hline$(5)$ & $2^{\text {nd }}$ hertical bending mode & - & - \\
\hline$(6)$ & $4^{\text {th }}$ vertical bending mode & 2.06 & 2.06 \\
\hline$(7)$ & $1^{\text {st }}$ torsional mode & 2.20 & 2.21 \\
\hline$(8)$ & $2^{\text {nd }}$ torsional mode & 2.36 & 2.36 \\
\hline$(9)$ & $3^{\text {rd }}$ torsional mode & - & - \\
\hline$(10)$ & $5^{\text {th }}$ vertical bending mode & 3.01 & 3.01 \\
\hline$(11)$ & $4^{\text {th }}$ torsional mode & 3.25 & 3.26 \\
\hline$(12)$ & $6^{\text {th }}$ vertical bending mode & 3.45 & 3.44 \\
\hline
\end{tabular}




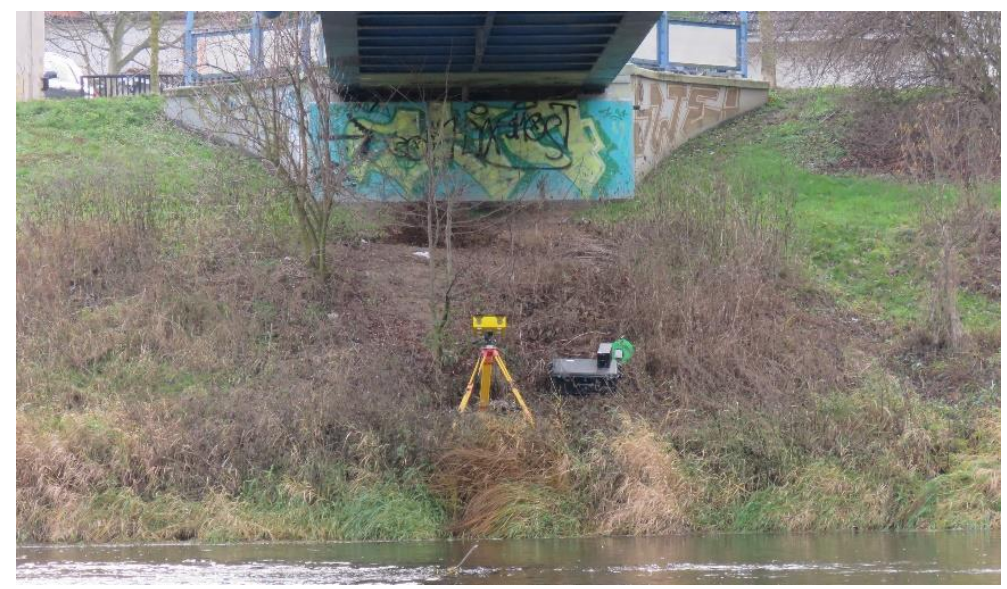

Fig. 10. The radar located under the footbridge in the course of the second stage of the experiment.

In the course of the second experiment stage, the footbridge vibrations were measured by two systems, conventional method using the same piezoelectric acceleration transducers as in the first case and new method using radar interferometry. Therefore, the natural frequencies of the footbridge could be evaluated again. The mutual comparison of the natural frequencies of the footbridge evaluated in the both experimental stages is shown in Table 4.

The differences between natural frequencies evaluated in 2017 and in 2019 are negligible and do not exceed the measurement precision. A detailed comparison of vibrations measured by the conventional method and the radar interferometry is still in progress.

\section{Dynamic load test}

The performed experimental modal analysis could not be evaluated on-line. Therefore, in the course of the first stage of the experiment, the natural frequencies of the footbridge for the purpose of the dynamic load test were evaluated in situ from three new records. During these records the transducers were placed to the positions in the longest span where the horizontal modes of vibration according the theoretical analysis have the maximal ordinates. Three natural frequencies missing in Table 3 were identified from these records as $1.34 \mathrm{~Hz}, 1.78 \mathrm{~Hz}$ and $2.66 \mathrm{~Hz}$.

\subsection{Measurement system}

The dynamic load test was performed with the same equipment as during the experimental modal analysis described in Chapter 3.1. The positions of the acceleration transducers during the dynamic load test are shown in Fig. 11. The selected points were designated 32, B2 and $\mathrm{C} 2$. At points 32 and $\mathrm{C} 2$, vibrations were measured in the vertical direction only and at point $\mathrm{B} 2$ in the vertical and horizontal directions. 


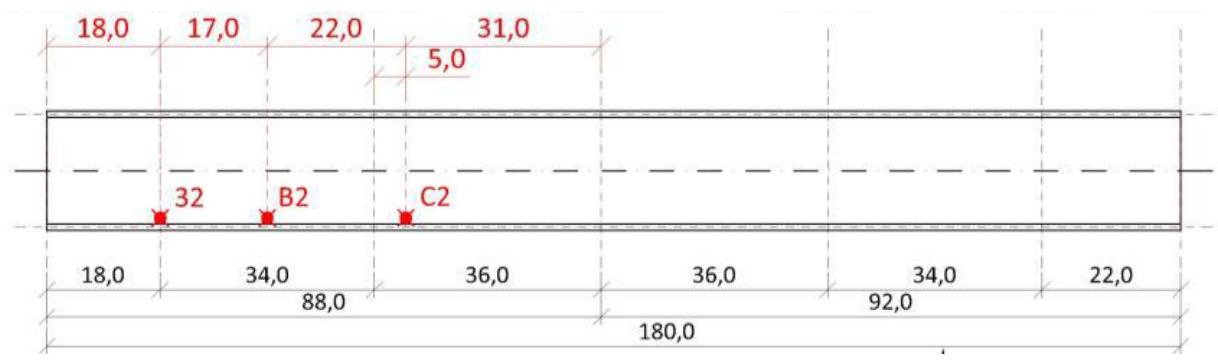

Fig. 11. The position of the acceleration transducers during the dynamic load test.

Three kinds of footbridge loading were used during the dynamic load test. The first one was normal pedestrian traffic. When the people went to or from a train station, the dynamic response of the footbridge was measured. The second kind was synchronous walk of two people with one of the natural frequencies from the frequency range $1.78 \mathrm{~Hz}$ to $3.28 \mathrm{~Hz}$. Synchronization was realized by a metronome. The third kind was vandalism. In the load cases focused on vandalism, the place near the position of $\mathrm{C} 2$ sensor was chosen to excite the structure. According to the theoretical analysis, the desired natural modes were expected to have the largest ordinates at this position, thus giving the greatest dynamic response. During the vandalism, the footbridge was excited by a group of nine people swaying in the knees synchronously with one of the identified natural frequencies.

\subsection{Evaluation of the dynamic response}

The measured records of footbridge vibrations were processed and the maximum peak values and RMS values of measured acceleration were calculated. These values were then assessed according to the criteria of pedestrian comfort defined in Czech standard ČSN 73 6209:1996 and also Eurocode ČSN EN 1990:2002.

In Eurocode, the recommended pedestrian comfort criteria for footbridges are defined as a maximum peak acceleration values. Comfort limit is set to $0.7 \mathrm{~ms}^{-2}$ for vertical vibration and $0.2 \mathrm{~ms}^{-2}$ for horizontal vibration. For horizontal vibration induced by exceptional load, a value of $0.4 \mathrm{~ms}^{-2}$ is recommended. Vandalism can be considered as an exceptional load in our case.

The maximal evaluated peak values of acceleration for two pedestrians walking on the footbridge were $0.61 \mathrm{~ms}^{-2}$ for the vertical vibration with the natural frequency $2.06 \mathrm{~Hz}$ (see Fig. 12) and $0.24 \mathrm{~ms}^{-2}$ for the horizontal vibration with the natural frequency $1.78 \mathrm{~Hz}$ (see Fig. 13). The maximal measured response for vandalism was $2.44 \mathrm{~ms}^{-2}$ (see Fig. 14).

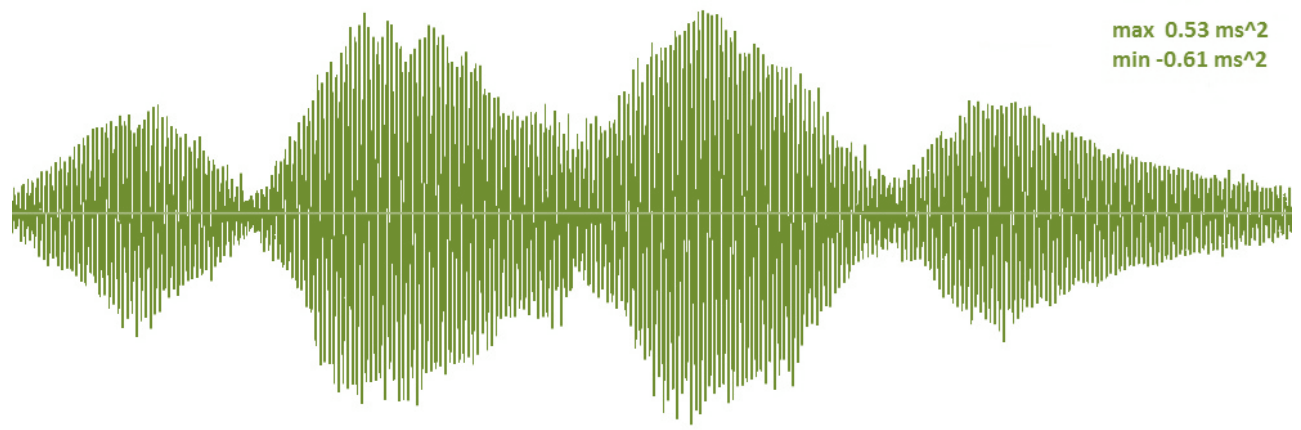

Fig. 12. The maximal measured vertical acceleration in the point $B 2$, two pedestrians walking synchronously with the natural frequency $f=2.06 \mathrm{~Hz}$. 


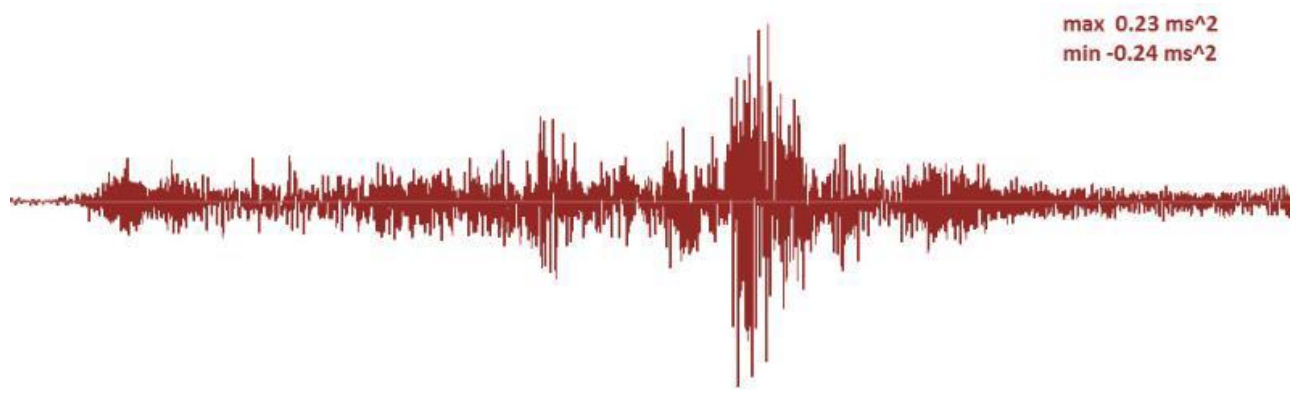

Fig. 13. The maximal measured horizontal acceleration in the point $\mathrm{C} 2$, two persons walking synchronously with the natural frequency $f=1.78 \mathrm{~Hz}$.

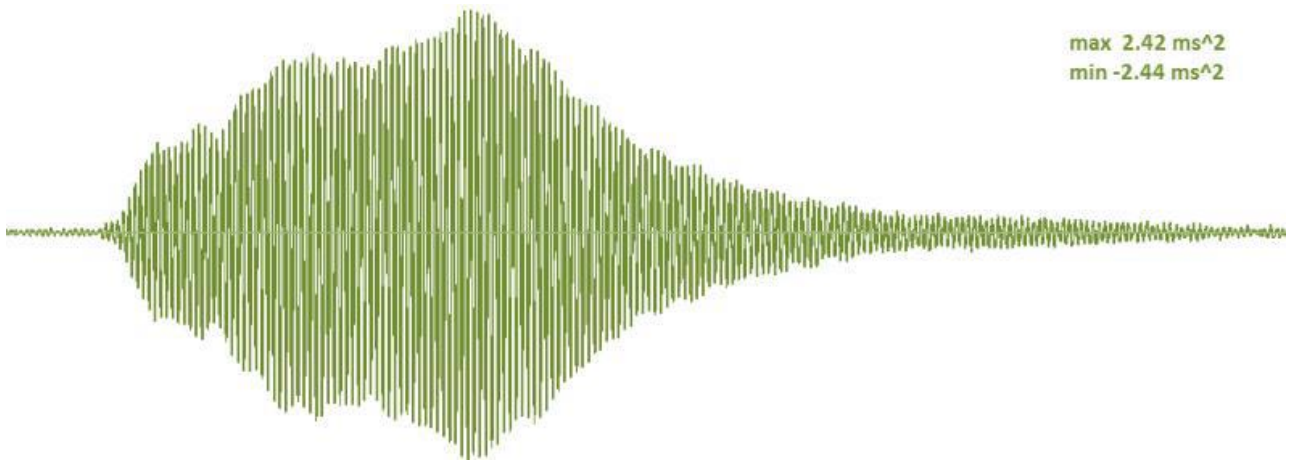

Fig. 14. The maximal measured vertical acceleration during vandalism.

In the Czech standard ČSN 73 6209:1996, pedestrian comfort criteria were defined in RMS values of acceleration. The pedestrian comfort limit by which the measured values were assessed depended on the frequency of vibration. Nevertheless, the minimal RMS value of this acceleration limit is $0.35 \mathrm{~ms}^{-2}$.

The maximal evaluated RMS value of measured acceleration for two pedestrians walking on the footbridge was $0.31 \mathrm{~ms}^{-2}$ for the vertical vibration with the natural frequency $2.06 \mathrm{~Hz}$. The maximal RMS value evaluated from the response to vandalism was $1.54 \mathrm{~ms}^{-2}$.

\subsection{Evaluation of damping}

The logarithmic decrement of the damping was evaluated for suitable records of the footbridge vibrations. It was evaluated using FFT multispectrum. Since the dynamic test did not interrupt traffic on the footbridge, most vibration records were not suitable for damping evaluation and the damped vibration of the structure was nicely recorded only in a few cases (see Fig. 15).

From the record focused on vandalism at $2.06 \mathrm{~Hz}$, logarithmic decrement $\delta=0.030$ was evaluated (see Fig. 15) and from vandalism records at $2.38 \mathrm{~Hz}$, the average logarithmic decrements $\delta=0.023$ was obtained. 

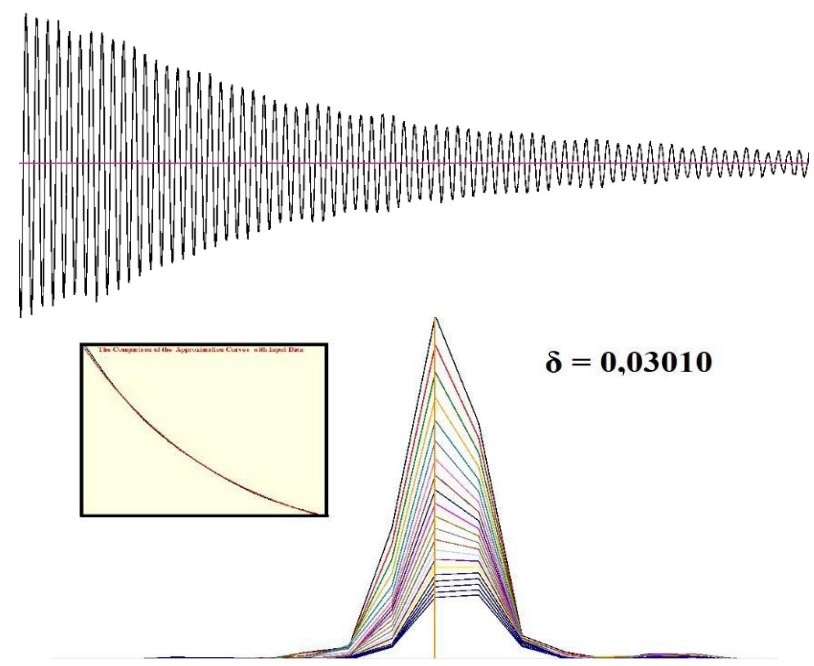

Fig. 15. The damping evaluation from the record focused on vandalism at $2.06 \mathrm{~Hz}$.

\section{Conclusions}

The results of the both experiment stages could be summarized to the following conclusions.

The differences between the corresponding calculated and measured natural frequencies of the footbridge (see Table 3) are very low and meet the limit deviations according to Czech standard (see Table 3 ) by a wide margin. The theoretical model of the footbridge is accurate enough and it is suitable for further dynamic analysis.

The differences between natural frequencies evaluated in the both experiment stages (see Table 4) are negligible and do not exceed the measurement precision. The important properties of the footbridge load-bearing structure did not change between 2017 and 2019.

The evaluated damping of the footbridge structure is relatively small. However, this fact does not influence negatively the level of usual footbridge vibrations.

The level of the evaluated footbridge vibrations induced by the standard pedestrian traffic did not exceed the comfort limits defined in Czech standards.

The results presented in this paper are outputs of the research project VI20192022167 "The Advanced Technology of Rapid Determination of Bridges Deformation by Radar Interferometry and its Use in Diagnostics" supported by Ministry of the Interior of the Czech Republic.

\section{References}

1. T. Plachý, M. Polák, P. Ryjáček, Procedia Engineer. 199 (2017)

2. P. Ryjáček, M. Polák, T. Plachý, J. Kašpárek, Procedia Structural Integrity 5 (2017)

3. M. Talich, International Archives of the Photogrammetry, Remote Sensing and Spatial Information Sciences - ISPRS Archives 42, 3W4 (2018)

4. M. Talich, IOP Conference Series: Earth and Environmental Science 95, 3 (2017)

5. C. Gentile, Radar Technology, (IntechOpen, Guy Kouemou, 2010)

6. I. Lipták, J. Erdélyi, P. Kyrinovič, A. Kopáčik, Geoinformatics FCE CTU 12 (2014)

7. B. Kafle, L. Zhang, P. Mendis, N. Herath, M. Maizuar, C. Duffield, R. G. Thompson, Int. J. Appl. Mech. 9, 1 (2017) 
8. M. Sokol, K. Lamperová, Vibroengineering PROCEDIA 23 (2019)

9. T. Owerko, P. Kuras, Shock and Vibration 2019 (2019)

10. R.J. Allemang, Brown D.L., Proceedings ISMA (2006)

11. P. Avitabile, Experimental Techniques 37, 2 (2015) 